\title{
Extraction-free detection of amphibian pathogens from water baths
}

\author{
Molly C. Bletz ${ }^{1, *}$, Brandon C. LaBumbard ${ }^{1}$, Emily H. Le Sage ${ }^{2}$, \\ Douglas C. Woodhams ${ }^{1}$ \\ ${ }^{1}$ University of Massachusetts Boston, Department of Biology, 100 Morrissey Blvd, Boston, MA 02125, USA \\ ${ }^{2}$ Department of Pathology, Microbiology and Immunology, Vanderbilt University School of Medicine, \\ Nashville, Tennessee 37212, USA
}

\begin{abstract}
Detecting and quantifying pathogens with quick, cost-efficient and sensitive methods is needed across disease systems for addressing pertinent epidemiological questions. Typical methods rely on extracting DNA from collected samples. Here we develop and test an extractionfree method from water bath samples that is both sensitive and efficient for 2 major amphibian pathogens - Batrachochytrium dendrobatidis and B. salamandrivorans. We tested mock samples with known pathogen quantities as well as comparatively assessed detection from skin swabs and water baths from field sampled amphibians. Quantitative PCR (qPCR) directly on lyophilized water baths was able to reliably detect low loads of 10 and 1 zoospores for both pathogens, and detection rates were greater than those of swabs from field samples. Further concentration of samples did not improve detection, and collection container type did not influence pathogen load estimates. This method of lyophilization (i.e. freeze-drying) followed by direct qPCR offers an effective and efficient tool from detecting amphibian pathogens, which is crucial for surveillance efforts and estimating shedding rates for robust epidemiological understanding of transmission dynamics. Furthermore, water bath samples have multiple functions and can be used to evaluate mucosal function against pathogens and characterize mucosal components. The multifunctionality of water bath samples and reduced monetary costs and time expenditures make this method an optimal tool for amphibian disease research and may also prove to be useful in other wildlife disease systems.
\end{abstract}

KEY WORDS: Batrachochytrium $\cdot$ Lyophilization $\cdot$ Pathogen detection $\cdot$ Wildlife disease $\cdot$ Early warning system

\section{INTRODUCTION}

Quick, cost-efficient and effective methods for detecting pathogens are needed across human, plant and wildlife disease systems. Techniques for detecting organisms, including pathogens, often involve quantitative polymerase chain reaction (qPCR), a highly sensitive technique, on extracted sample DNA. In recent years, qPCR has been the method of choice and has been shown to be a highly sensitive technique for detection of important amphibian pathogens (Boyle et al. 2004, Blooi et al. 2013). These

*Corresponding author: molly.bletz@gmail.com pathogens, namely Batrachochytrium dendrobatidis and $B$. salamandrivorans ( $B d$ and $B s a l$ ), are a cause of global losses in amphibian diversity and shifting ecosystems, making early detection as well as continuous monitoring important endeavors (Weldon et al. 2013, Gray et al. 2015, Waddle et al. 2020). Furthermore, teasing apart transmission dynamics and building robust models from pathogen load data can shape our understanding of infection and disease dynamics (Wilber et al. 2017).

For amphibians, water bath samples have been used for various purposes, including estimation of

() The authors 2021. Open Access under Creative Commons by Attribution Licence. Use, distribution and reproduction are unrestricted. Authors and original publication must be credited. 
pathogen shedding rates (Hyatt et al. 2007) as well as evaluating mucosal function as an assay for protectiveness of skin secretions and proxy for host susceptibility (Woodhams et al. 2014, Smith et al. 2018). For shedding rates, qPCR is typically performed on DNA extracted from filters of water that previously housed an amphibian host (Reeder et al. 2012, DiRenzo et al. 2014). DNA extraction has been seen as an essential step for performing qPCR as it lyses cells to expose the genomic DNA and purifies the DNA by removing cell debris and other components that can inhibit the qPCR reactions. Extraction methods with the highest efficiency and purity can be expensive and time-consuming while quick methods can often fail to detect low pathogen loads (i.e. have low sensitivity) (Bletz et al. 2015, Brannelly et al. 2020) or inhibit PCR (PrepMan; Boyle et al. 2004).

Mucosal function assays have employed lyophilization of samples to concentrate skin secretions and evaluate their potential to inhibit or kill pathogen cells. Lyophilization is a process that sublimates water from frozen samples, i.e. freeze drying, and requires a standard piece of equipment found in most chemistry or biology departments. This process has the potential to lyse cells or minimize the integrity of cell membrane/walls, and therefore, may make sample DNA available for PCR amplification without formal DNA extraction protocols. Likewise, PCR thermo-cycling can also lyse cells making DNA accessible (Flores et al. 2012, Videvall et al. 2017); therefore, lyophilization coupled with PCR thermocycling has the potential to amplify target DNA and allow for detection and quantification of pathogen loads.

Here we develop and test an extraction-free pathogen detection method from water baths by (1) evaluating efficiency and sensitivity of pathogen detection from mock water baths to which we added known concentrations of $B d$ and Bsal zoospores, (2) comparing pathogen quantity estimates from water bath collections in plastic and glass given the surface adherence noted in Hyatt et al. (2007), and (3) assessing $B d$ detection across skin swab and water bath samples from field sampled amphibians given the standard use of swabs in amphibian disease research. It is essential to have a method with high efficiency and sensitivity in order to accurately determine the presence and intensity of the chytrid fungus. Low efficiency and sensitivity could result in false negatives, which can have important consequences for amphibian conservation and disease mitigation decisions and inaccurate modelling of infection and transmission dynamics in natural systems.

\section{MATERIALS AND METHODS}

\subsection{Sample preparation and collection}

Mock water bath samples of $\sim 12 \mathrm{ml}$ of artificial pond water (e.g. Provasoli following Wyngaard \& Chinnappa 1982; recipe details in Robinson et al. 2020) were prepared and spiked with a dilution series of $1 \times 10^{6}$ to $1 \times 10^{0} \mathrm{Bd}$ and Bsal zoospores to mimic mucosome baths used for mucosal function assays and $1 \mathrm{~h}$ shedding rate bath collections. Five replicates of each spike-in dose were prepared ( $\mathrm{n}=35)$, in addition to 5 negative controls containing only artificial pond water. Bd (JEL 423) and Bsal (AMFP13/1) were maintained in $1 \%$ tryptone broth. $B d$ zoospores were harvested from tryptone agar plates that were seeded with $1 \mathrm{ml}$ of 3-5 d old liquid cultures, and Bsal zoospores were harvested from synchronized liquid cultures (Robinson et al. 2020). Artificial pond water was used for harvesting both pathogens. Harvested zoospores were subsequently counted on a hemocytometer with 4 replicate counts by 3 individuals. Dilutions of $10^{6}-10^{0}$ zoospores were prepared in artificial pond water so $1 \mathrm{ml}$ of prepared zoospore solutions could be added to the mock water baths to obtain the target spike in amounts. Samples were then frozen in $15 \mathrm{ml}$ conical tubes at $-80^{\circ} \mathrm{C}$, lyophilized, and rehydrated in $1 \mathrm{ml}$ sterile Milli-Q water. For lyophilization, $15 \mathrm{ml}$ tubes (HDPE, CellTreat \# 229411) were uncapped, covered with parafilm, and made porous by pricking 3-5 holes in the parafilm to allow sublimation while also protecting the sample contents. The lyophilizing procedure was carried out on a LabConco FreezeZone 2.51 Benchtop System; the temperature was $-85^{\circ} \mathrm{C}$ and the pressure was $0.006 \mathrm{mBar}$.

Additionally, 6 field water bath samples (collection methods followed field procedure outlined below) from swab-positive leopard frogs were processed to demonstrate if detection occurs from 'complex' samples containing amphibian secretions. Initial rehydration was performed in a 'concentrated' form where a smaller volume of $100 \mu$ l was used to see if detection increased or was hindered by concentration. (See 'Supplementary methods' and 'Supplementary results' in the Supplement for more details; www.int-res.com/articles/suppl/d146p081_supp.pdf). Samples were subsequently diluted 1:10 in MilliQ water to equate to adding $1 \mathrm{ml}$ to the lyophilized sample, which is standard for mucosome function testing from water bath samples.

An additional trial was performed to determine if completion of $1 \mathrm{~h}$ water baths in plastic (e.g. WhirlPaks) versus glass jars affected qPCR detection esti- 
mates. To test this, Bsal zoospores were quantified using 4 replicate counts on a hemocytometer, and $1000 \mathrm{Bsal}$ zoospores were spiked into $12 \mathrm{ml}$ of artificial pond water in both Whirl-Pak bags and Pyrex glass containers. Seven replicates of Bsal spike-in samples and 3 controls containing only $12 \mathrm{ml}$ of artificial pond water were prepared in each container type (total $\mathrm{N}=20$ ) and incubated for $1 \mathrm{~h}$. After $1 \mathrm{~h}$, mock baths were transferred to $15 \mathrm{ml}$ plastic conical tubes, frozen, lyophilized, and rehydrated in $1 \mathrm{ml}$ of sterile Milli-Q water.

Lastly, we compiled data from 313 field-collected $1 \mathrm{~h}$ skin washes and skin swabs to assess whether skin wash and swab values mirror each other. Postmetamorphic leopard frogs (Lithobates [Rana] pipiens, $\mathrm{n}=105 ;$ L. sphenocephalus, $\mathrm{n}=167 ;$ L. blairi, $\mathrm{n}=$ 41) were sampled in rural ponds and surrounding habitats at 5 locations including Vermont, Pennsylvania, Tennessee, Louisiana, and New Mexico, USA, between February and November of 2017. Sampled leopard frogs ranged from $0.8-83.0 \mathrm{~g}$ in mass (measured using a Pesola scale). Individuals were first swabbed following Hyatt et al. (2007) with rayontipped swabs (Medical Wire, MW113). Fresh, clean pairs of gloves were used for each individual to avoid cross contamination. Swabs were stored in $1.5 \mathrm{ml}$ tubes. Subsequently, $1 \mathrm{~h}$ water baths were collected by bathing the frog in $15 \mathrm{ml}$ of artificial pond water in sterile Whirl-Pak bags. Three water bath controls were taken during field sampling where the sampling procedure was completed without an amphibian being placed in the bag. After the bath, washes were transferred to 15 or $50 \mathrm{ml}$ conical tubes for storage. Both swabs and washes were stored on ice until access to a -20 or $-80^{\circ} \mathrm{C}$ freezer was possible.

\subsection{Molecular methods}

For all water bath samples, $B d / B s a l$ qPCR duplex reactions that amplify the internal transcribed spacer (ITS) region were run directly on the rehydrated samples following Blooi et al. (2013). For swab samples, DNA was first extracted using a Qiagen Blood and Tissue Kit following the manufacturer's protocol for animal tissue with one modification of a double elution step to increase total DNA yield (final vol. = $200 \mu \mathrm{l}$ ). For all qPCR reactions (bath and swab extracts) $5 \mu \mathrm{l}$ of DNA was added to the reactions. For mock water bath samples, AzuraQuant Probe Fast qPCR Mix (2X), and all qPCR reactions were performed in duplicate (or triplicate in some cases) on a BioRAD CFX machine. gBLOCK standards were used to estimate ITS copies of both $B d$ and Bsal in samples (Standish et al. 2018). Samples were considered positive when at least 2 qPCR replicates had a positive amplification signal with typical amplification curves. Estimated copies from the qPCR were adjusted to represent total sample volume; that is, we divided by 5 to get a per $\mu$ l estimate and then multiplied the estimate by 200 to account for total extraction volume from swab samples or by 1000 to account for total rehydration volume of $1 \mathrm{ml}$ for water bath samples.

For the field samples, the same duplex reaction protocol was followed (Blooi et al. 2013), except bovine serum albumin (final concentration $400 \mathrm{ng}$ $\mu^{-1}, 1 \mu \mathrm{l}$ in $25 \mu \mathrm{l}$ reaction; Garland et al. 2010) was added to each sample to minimize potential inhibition. SensiFAST Probe Lo-ROX qPCR Mix (2X) was used for these samples. An internal positive control (IPC) (Hyatt et al. 2007) was also included in each sample to allow for evaluation of inhibition within qPCR reactions. Ten water bath samples were re-run at a 1:10 dilution due to IPC-detected inhibition. Standards consisted of a 7 -fold dilution series of plasmid-based $B d$ and $B s a l$ sequences $\left(4.2 \times 10^{6}-4.2\right.$ plasmid copies $\mu^{-1}$; Pisces Molecular). These 313 field samples are part of another ongoing study, and each swab extract and field water bath was tested in singlicate to maximize cost efficiency (Kriger et al. 2006). Estimated loads from the qPCR were adjusted to represent total extraction and rehydration volume for swabs and baths, respectively, as described above. All swab extraction controls, field water bath controls, and qPCR negative controls were negative for $B d$ and Bsal.

\subsection{Data analysis}

All statistical analyses and plot generation were completed in R v4.0.2 (R Core Team 2020). The proportion of samples with positive detections was calculated across the spiked water bath samples for $B d$ and Bsal as well as the field samples in the standard and concentrated preparations. Fisher's exact tests and generalized linear models (GLM) with a binomial distribution were used to analyze detection (i.e. presence/absence). Estimated ITS copies were compared using linear models (LM) and Kruskal-Wallis (KW) tests depending on data distributions. Additionally, Kendall-tau correlations were calculated across the dilution series of both pathogens as well as for the standard and concentrated spike-in samples. Correlations were also calculated between swab and water 
bath estimates from field-collected samples. Detection rates of swabs and water baths were calculated from the field-collected samples, and Bayes theorem was used to calculate conditional probabilities.

\section{RESULTS}

\subsection{Direct qPCR from water baths exhibits high sensitivity}

Detection from direct lyophilized mock water baths occurred in 5/5 samples for both $B d$ and Bsal for the $10^{6}-10^{2}$ spike-in doses. Detection was $4 / 5$ and $3 / 5$ at the 10 zoospore spike in and $4 / 5$ and $1 / 5$ at the 1 zoospore spike in for $B d$ and $B s a l$, respectively (Fig. 1). All negative control bath samples were negative for $B d / B s a l$ in $q P C R$. Detection did not differ from $100 \%$ across doses for $B d$ and only dropped significantly for Bsal at the 100 spike-in dose (Fisher's exact: $\mathrm{p}=$ 0.048). Detection did not significantly differ between $B d$ and $B$ sal at spike-in doses of $10^{6}-10^{1}$ (Fishers exact: $\mathrm{p}>0.05$ ), but detection was significantly lower at the 1 zoospore spike-in quantity for Bsal compared to $B d$ (Fisher's exact: $\mathrm{p}=0.033$ ). Furthermore, there was a strong correlation between the number of zoospores spiked into the samples and the number of ITS copies detected via qPCR for both $B d$ and $B s a l$ $\left(B d-\mathrm{LM}: \log _{10}\right.$ zoospores added, $F_{(33,1)}=343.0, \mathrm{R}^{2}=$
0.91, p < 0.001; Bsal-LM: $\log _{10}$ zoospores added, $F_{(31,1)}=160.2, \mathrm{R}^{2}=0.83, \mathrm{p}<0.001$; Fig. 1). Concentrated water bath samples (i.e. those rehydrated in $100 \mu \mathrm{l})$ minimized pathogen detection compared to samples with the $1 \mathrm{ml}$ rehydration volume and resulted in spurious, atypical amplification curves (see the Supplement).

\subsection{Collection container does not affect pathogen detection}

Bsal was detected in all spike-in samples from both container types ( $\mathrm{n}=7$ each), and control samples were all negative for Bsal ( $\mathrm{n}=3$ each). Estimated Bsal ITS copies from mock water bath samples did not differ between Whirl-Pak and glass collection jars (Whirlpak $=1.55 \times 10^{4} \pm 2.15 \times 10^{3}[$ mean $\pm \mathrm{SE}]$, glass $=1.89$ $\times 10^{4} \pm 1.76 \times 10^{3} ;$ GLM: $F_{1,28}=1.28, \mathrm{p}=0.270$ ).

\subsection{Water bath samples exhibit higher detection rate than swabs}

Quantitative PCR was performed on extracted swab DNA and lyophilized water baths collected from 313 field samples from Lithobates pipiens, $L$. sphenocephalus and L. blairi. All field collected control samples $(\mathrm{n}=3)$, swab extraction controls (1/ex-
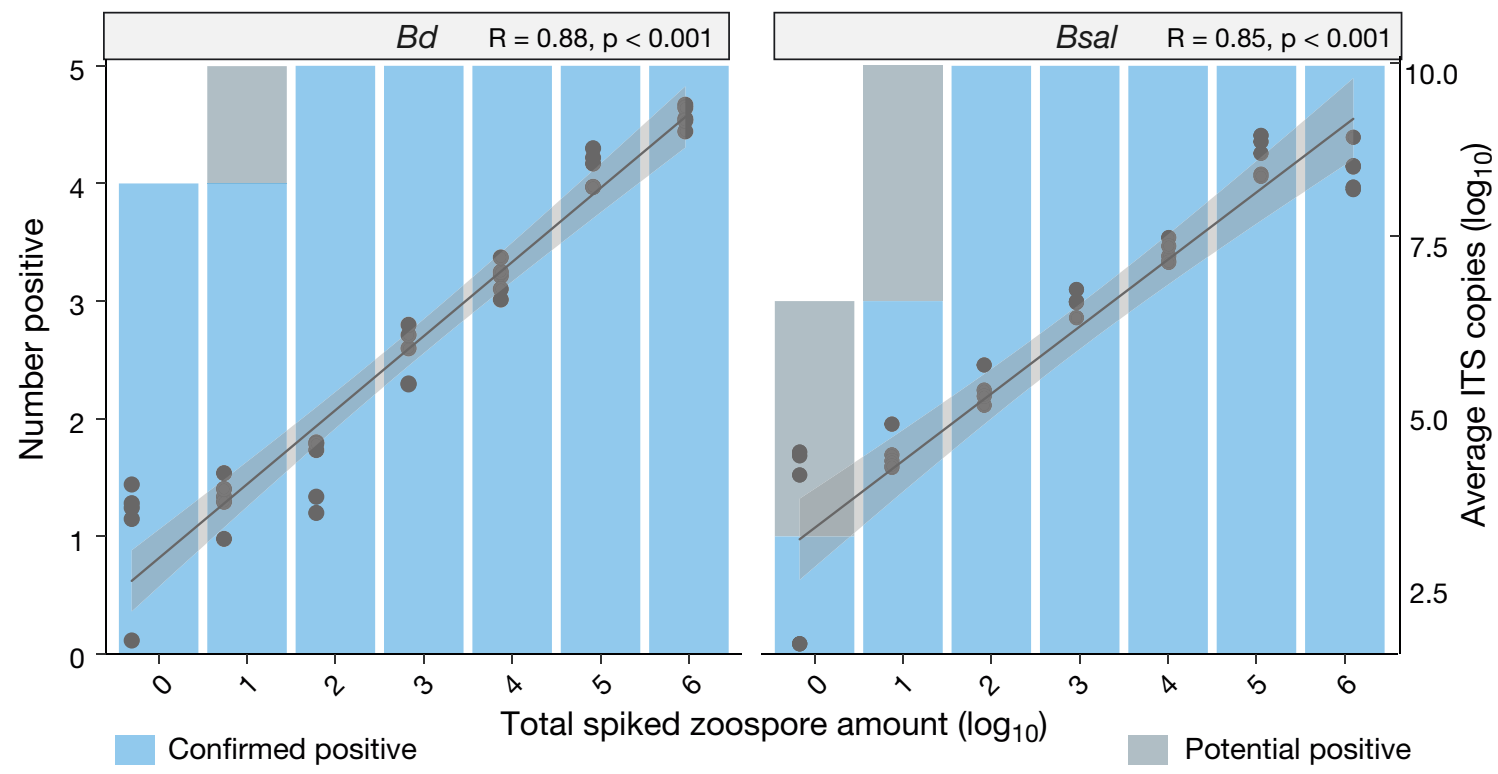

Fig. 1. Detection of $B d$ and Bsal from direct quantitative PCR (qPCR) testing from lyophilized water baths spiked with known zoospore quantities. Left axis: count of positive samples (i.e. detection). Blue fraction of bar: samples with clear duplicate or triplicate qPCR amplifications (i.e. confirmed positives); gray fraction: samples with singlicate qPCR amplification (1/2 or 1/3, i.e. unconfirmed positives). Right axis: average $\mathrm{Bd} / \mathrm{Bsal}$ internal transcribed spacer (ITS) copies estimates corresponding to the linear fit lines 
traction set) and qPCR negative controls (1/plate) tested negative for $B d / B s a l$ by qPCR. Bd-ITS copy estimates from swab extracts and water baths were significantly correlated (Kendall: $\mathrm{R}=0.36, \mathrm{p}<0.001$; KW: $\chi^{2}=222.4, p<0.001$, Fig. 2). Swab extracts and water baths had matched results in $69 \%$ of the samples. A total of 134 samples were negative for $B d$ in both swabs and water baths, 81 samples were positive for both swabs and water baths (i.e. matched detection), 63 were positive only for water baths, and 35 were positive only for swab extracts. If any detection is considered true (therefore combining positive matches, water bath only, and swab only, $\mathrm{n}=179$ ), the detection rate from water baths was $80 \%(20 \%$ failure rate) and $65 \%$ for swabs (35\% failure rate). Furthermore, for all species, water baths showed higher detection rates than swabs (Table S1 in the Supplement). Using Bayes theorem to calculated conditional probabilities, we found that there was a $60 \%$ chance of detecting $B d$ from a swab if $B d$ was detected in the water bath, and there was a $71 \%$ chance of detecting $B d$ from the water bath if $B d$ was detected on the swab. Of the samples where both were positive $(\mathrm{n}=81), 53$ had higher ITS copy estimates from water baths and 29 had higher estimates

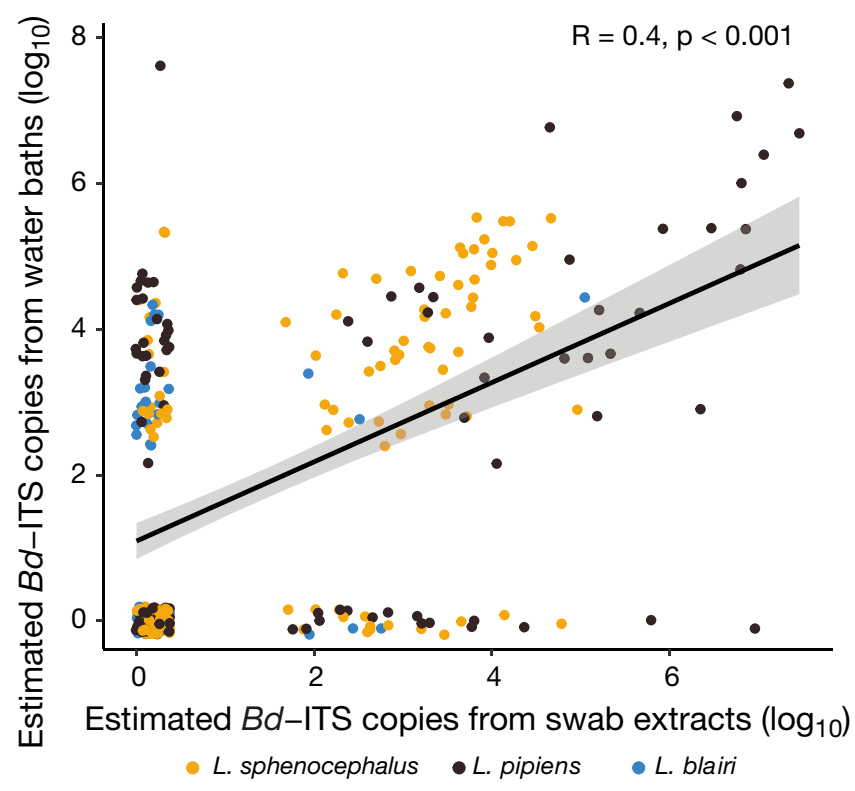

Fig. 2. Relationship between $B d$ internal transcribed spacer (ITS) copies estimated from swab extracts and $1 \mathrm{~h}$ water bath from field sampled frogs. Points representing zeros for either axis have been jittered with ggplot::geom_jitter to allow visualization of overlapping points. Non-zero values are displayed un-jittered. Points are colored by host species: blue: Lithobates blairi; black: L. pipiens; yellow: L. sphenocephalus. Kendall-tau correlation results denoted in the upper right from skin swabs. Furthermore, the average number of estimated ITS copies from skin washes was significantly lower for samples where only the skin wash sample detected $B d$ compared to samples where both skin wash and swab detected $B d$ (wash only: $1.04 \times 10^{6} \pm 1.02 \times 10^{6}(\mathrm{SE})$; matched: $6.24 \times 10^{5} \pm 3.23$ $\left.\times 10^{5}(\mathrm{SE}) ; \mathrm{KW}: \chi^{2}=10.032, \mathrm{p}=0.002\right)$.

\section{DISCUSSION}

Water bath samples from amphibians are used for a variety of purposes including mucosal function assays (Woodhams et al. 2014, Smith et al. 2018), pathogen detection (Shin et al. 2014), and pathogen shedding rate (Reeder et al. 2012, DiRenzo et al. 2014). The purpose of this study was to develop and evaluate a protocol for pathogen detection and quantification from water bath samples without inclusion of a DNA extraction step. We found that qPCR on the directly lyophilized water bath samples rehydrated in $1 \mathrm{ml}$ of ultrapure water can not only detect 2 major amphibian pathogens, $B d$ and $B s a l$, but can do so with high sensitivity (i.e. detect low pathogen loads). Furthermore, we found that the type of water bath collection container (plastic vs glass) had no effect on estimated pathogen loads and that 'concentrating' samples through rehydration in less than $1 \mathrm{ml}$ resulted in qPCR inhibition, which, at times, led to a failure to detect the pathogens altogether. Finally, we found that overall water bath and swab extracts correlated in their estimated $B d$ quantity, and Bayes theorem suggests our protocol from water bath samples may be moderately better at detecting $B d$ compared to swabs. Collectively these results show that our protocol for water bath samples is effective and highly sensitive and may outperform standard swabbing for pathogen detection. Furthermore, this means pathogen detection, estimate of shedding rates, and mucosal function can be determined from a single sample, reducing cost and combined time during field and wet lab procedures (Table 1).

Quantitative PCR on extracted DNA is a standard and widely used method for detection of specific pathogens in and on host organisms. In amphibian systems DNA extraction from skin swabs and filters from water baths followed by qPCR have been used for pathogen detection and shedding rate calculations from host amphibians (Reeder et al. 2012, DiRenzo et al. 2014). Herein, we show pathogens can be efficiently detected by our simple method of lyophilizing (freeze-drying) collected water baths and performing $\mathrm{qPCR}$ directly on the rehydrated 
Table 1. Comparison of water bath and swab sampling broken down by field sampling, sampling processing, and detection rate. Cost estimates, hands-on time, and number of samples are provided. Elements of sampling and processing that are equal between methods are excluded (e.g. capture time, quantitative PCR, freezers)

\begin{tabular}{|c|c|c|}
\hline Field sampling & Water bath & Swab \\
\hline Sample time & $\begin{array}{l}60-75 \text { min ( } 60 \text { min bath of individuals } \\
\text { + transfer time) for } 30 \text { individuals }\end{array}$ & $30-40$ min for 30 individuals \\
\hline Supplies & $\begin{array}{l}\text { Collection bags, } 15 \mathrm{ml} \text { tubes, artificial } \\
\text { pond water, ice cooler }\end{array}$ & $\begin{array}{l}\text { Collection bags, swabs, } 1.5 \mathrm{ml} \text { tubes, ice cooler } \\
\text { (optional) }\end{array}$ \\
\hline $\begin{array}{l}\text { Sample processing } \\
\text { time }\end{array}$ & $\begin{array}{l}15 \text { min of hands-on time } \\
\text { (total time to obtain final DNA 'extract' }=48 \mathrm{~h} \text { ) }\end{array}$ & $\begin{array}{l}2-2.5 \mathrm{~h} \text { hands-on time } \\
\text { (total time to obtain final DNA 'extract' }=3 \mathrm{~h} \text { ) }\end{array}$ \\
\hline Sample number & $\begin{array}{l}60 \text { samples at a time (assuming } 4 \text { nozzle } \\
\text { benchtop lyophilizer) }\end{array}$ & $\begin{array}{l}24 \text { samples at a time (assuming } 24 \text { rotor } \\
\text { centrifuge and single tube extractions) }\end{array}$ \\
\hline Freezer space & Space for $15 \mathrm{ml}$ tubes & Space for $1.5 \mathrm{ml}$ tubes \\
\hline Cost & $\$ 0$ (USD) per sample & $\$ 2.30-3.04$ (USD) per sample \\
\hline Equipment & $\begin{array}{l}\text { Lyophilizer, Vortex } \\
\text { Cost: } \$ 18000+\$ 350=\$ 18350 \text { (USD) }\end{array}$ & $\begin{array}{l}\text { Centrifuge, Heat block, Vortex } \\
\text { Cost: } \$ 1800+\$ 800+\$ 350=\$ 2950 \text { (USD) }\end{array}$ \\
\hline Detection rate & $80 \%$ & $65 \%$ \\
\hline
\end{tabular}

Collection \& Processing Protocol detection of pathogens from water baths

(1) Bath amphibian in 12-15 ml of sterile artificial pond water within a Whirl-pak bag for $1 \mathrm{hr}$.

(2) Transfer bath solution to a 15 or $50 \mathrm{ml}$ conical tube and freeze at $-80^{\circ} \mathrm{C}$.

(3) Once frozen, prepare samples by partially unscrewing the caps to allow sublimation.

(4) Place on lyophillizer and lyophilize until dry.

(5) Resuspend dried sample in $1 \mathrm{ml}$ of ultrapure (e.g. MilliQ) water, vortex $\sim 10 \mathrm{sec}$, and centrifuge for $10 \mathrm{sec}$. ${ }^{*}$ DO NOT use a rehydration solution with added salts Optional. Transfer the $1 \mathrm{ml}$ to a $1.5 \mathrm{ml}$ tube for ease of storage.

(6) Run a standard qPCR reaction with $5 \mu$ of sample. of the resuspension liquid.

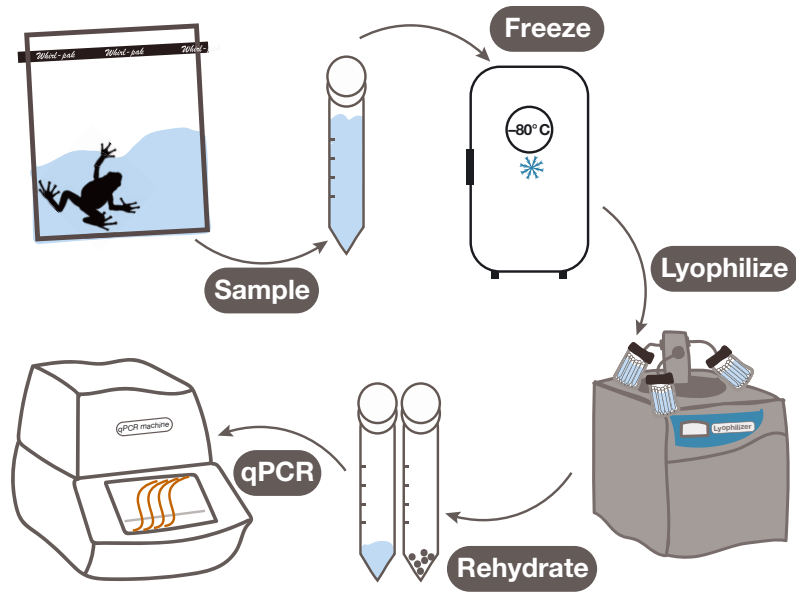

Fig. 3. Step by step protocol for pathogen detection from water bath method

products, bypassing the DNA extraction step (Fig. 3). Both Batrachochytrium pathogens were detectable with high sensitivity. The detection limit mirrored that of optimal DNA extraction methods (see swab extraction comparisons in Bletz et al. 2015 and Brannelly et al. 2020) with detection only being significantly reduced for the 1 zoospore level. This reduction in detection was observed for Bsal only and not $B d$. This difference may be associated with ITS copy number differences between the pathogens, which has been reported for different strains of $B d$ (Longo et al. 2013, Rebollar et al. 2017). If Bsal has lower copies per genome, capturing and successfully amplifying DNA with low zoospores amounts could be below the threshold of detection. Alternatively, the existence of encysted spores with more robust cell walls for $B s a l$ (but not $B d$ ) may also contribute to this, given it likely makes it more difficult to access the DNA in these more robust spores (Stegen et al. 2017).

Bypassing the extraction step can reduce both supply costs and hands-on lab time (Table 1). While lyophilizers might not be present in every molecular lab, it is a typical piece of equipment within biology or chemistry departments at universities with multifunctionality across fields (e.g. Rockinger et al. 2021). Multiple studies have proposed cost-saving measures at the extraction and qPCR step through extraction pooling (Hyatt et al. 2007, Sabino-Pinto et al. 2019a,b), and singlicate qPCR (Kriger et al. 2006). For efficient DNA extraction kits that produce high-quality, pure DNA, costs are approximately \$2.30-\$3.04 USD per 
sample (catalog prices for IBI and Qiagen), and hands-on lab time to complete a standard spin column extraction is approximately $3 \mathrm{~h}$ (Sabino-Pinto et al. 2019a). The method tested here, therefore, is one of the most economical and person-time efficient approaches available (Table 1). With that said, it is important to consider that for certain field sites which involve traversing rough terrain on foot, carrying water and ice packs may be challenging. Furthermore, if pathogen surveillance is the only purpose of sampling, it would be likely more time efficient in the field to swab amphibians; however, it will be important to factor in lab time and detection probability when making method decisions.

Plastic vials and bags are commonly used for amphibian samples; previous studies have suggested that zoospores and cellular material can stick or adhere to collection container surfaces (Hyatt et al. 2007). However, we found that HDPE plastic and glass vials yielded matching results. The short duration of bath time $(1 \mathrm{~h})$ may reduce potential adherence. This result is useful in the context of field research where bringing large numbers of glass jars could be cumbersome.

It is important to note that qPCR amplification and detection was not improved by rehydrating samples in smaller volumes (i.e. concentrating the sample by $10 \times$ ). While concentrating DNA in highly pure samples can be seen as a way to increase the likelihood of detection, in this case the opposite occurred; the reaction was hindered. In fact, concentrating the samples reduced detection and estimated quantities, and caused atypical exponential curves. While no IPC controls were run to confirm inhibition, this failure of the qPCR reactions is likely due to increased salt concentrations (as demonstrated by nanodrop 260:230 reading less than 1.8; range of tested samples: 0.06-0.3), which interfere with the Taq polymerase or other components of the qPCR reaction (Schrader et al. 2012). Water baths of amphibians are necessarily completed in a water solution with added ions (e.g. Provasoli, reconstituted reverse osmosis water) to minimize interfering with the osmotic balance across sensitive amphibian skin. During lyophilizing, this salt and other sample contents are dried and therefore concentrated when rehydrated. Minimizing the rehydration volume to less than $1 \mathrm{ml}$ or rehydrating in a solution containing ions, therefore, can push salt concentrations to levels not suitable for qPCR. For baths of smaller individuals or larval stages, a reduced bath volume could also help reduce the amount of salt being rehydrated, here we used up to $15 \mathrm{ml}$ of bath water with no apparent
qPCR inhibition when rehydrated in $1 \mathrm{ml}$ Milli-Q water. Importantly, amphibians have different shapes, sizes, and secretions; therefore, soaking and rehydration volumes may need to be validated and adjusted depending on the study system. Further testing to evaluate the effects of environmental conditions (e.g. temperatures and other field conditions) that may affect DNA degradation and PCR inhibition may also be important.

Furthermore, our tested field samples did not experience significant qPCR inhibition (successful amplification of the internal standard) in either water bath or swab samples. There were 10 water bath samples that did show inhibition; when rerun at a 1:10 dilution, inhibition was ameliorated, and samples were negative for $B d$. We cannot exclude the possibility that this dilution influenced the ability to detect $B d$ by pushing it below the detection limit. Inhibition in water baths could have potentially occurred due to increased environmental debris or feces, indicating the importance of reducing these in the bath before freezing. Importantly, the majority of field samples $(96.8 \%)$ amplified with no inhibition, suggesting that frog secretions are unlikely to affect detection. Continued inclusion of IPCs should be considered standard even though these data suggest inhibition is low.

As compared to skin swabs, water bath sample collection may serve as a more robust technique for detecting amphibian pathogens, $B d$ and $B s a l$. Swabbing amphibians is a standard method widely used in amphibian disease research (Hyatt et al. 2007) for pathogen detection and quantification. While, overall, swabs and water bath results correlate, mirroring results of some studies (Reeder et al. 2012, compared to tissue in Hall et al. 2020), detection probabilities from water baths were greater than swabs. This improvement in detection of $B d$ in water baths should also be considered conservative, as some zoospores that may have been added to the water bath samples were first swabbed from the skin. This finding is similar to that of Shin et al. (2014), who found that swabs can also miss lower-level infections compared to water baths. Indeed, we found that the average estimated quantity from skin washes was significantly lower for samples where only the skin wash sample detected $B d$ compared to samples where both sample types showed detection, suggesting the washes can detect lower infection loads. Our results add to their study, showing that baths of only $1 \mathrm{~h}$ (vs. 12, $24 \mathrm{~h}$ in Shin et al. 2014) are effective and more robust than swabs for detection. Water baths had a $15 \%$ lower failure rate than swabs and showed no evi- 
dence of contamination from field collection or sample processing. Water baths also remove some common biases associated with swabbing, such as surface area swabbed, swabbing pressure, number of swabbing motions, and other factors (Simpkins et al. 2014). Water baths also remove the harmful effects of swabbing delicate larvae, which can sometimes lead to death when swabbing oral disks of tadpoles and the thin skin of larval salamanders (authors' pers. obs.). We also note the importance of using artificial pond water, rather than pure water, for bathing larval amphibians sensitive to osmotic stress. Detection from water baths may be greater than from swabs given that shedding seems to be uneven through time, making the prolonged sampling duration of a water bath more likely to pick up pathogen cells (Shin et al. 2014). Contact with water may also promote zoospore discharge. Further testing with shorter bath durations may reveal optimal field handling times for pathogen surveillance. Furthermore, water bath samples also can provide additional data, e.g. shedding rates and mucosal function, which can synergize to address questions in the disease ecology of amphibian systems. Estimating shedding rates can add valuable information about individual amphibian contributions to transmission and infection dynamics (Wilber et al. 2017), and mucosal function assays can provide crucial information on host susceptibility (Woodhams et al. 2014). Perhaps water baths of other potential pathogen reservoir hosts, such as crayfish (McMahon et al. 2013), will prove useful when swabbing is not possible.

The multifunctionality of water bath samples, better detection rates, reduced monetary costs, and hands-on time expenditures make this method a useful tool for amphibian disease research systems, and it may also prove to be useful in other wildlife disease systems.

Acknowledgements. We thank Michel Ohmer, Laura Brannelly, Nina McDonnell, Mason Ryan, Ian Latella, and Jamie Voyles for assistance with field sample collection, and Dan Wetzel, Caitlin Nordheim, and Joana Sabino Pinto for assistance with laboratory sample processing. We thank Cori Richards-Zawacki for coordination of the SERDP project team. This investigation was funding by SERDP Contract RC-2638 to D.C.W., NSF EEID grant 1814520 to D.C.W., and David H. Smith Postdoc Fellowship to M.C.B.

\section{LITERATURE CITED}

Bletz MC, Rebollar EA, Harris RN (2015) Differential efficiency among DNA extraction methods influences detection of the amphibian pathogen Batrachochytrium dendrobatidis. Dis Aquat Org 113:1-8
Blooi M, Pasmans F, Longcore JE, Spitzen-Van Der Sluijs A, Vercammen F, Martel A (2013) Duplex real-time PCR for rapid simultaneous detection of Batrachochytrium dendrobatidis and Batrachochytrium salamandrivorans in amphibian samples. J Clin Microbiol 51:4173-4177

Boyle DG, Boyle DB, Olsen V, Morgan JAT, Hyatt AD (2004) Rapid quantitative detection of chytridiomycosis (Batrachochytrium dendrobatidis) in amphibian samples using real-time Taqman PCR assay. Dis Aquat Org 60:141-148

*Bannelly LA, Wetzel DP, West M, Richards-Zawacki CL (2020) Optimized Batrachochytrium dendrobatidis DNA extraction of swab samples results in imperfect detection particularly when infection intensities are low. Dis Aquat Org 139:233-243

*DiRenzo GV, Langhammer PF, Zamudio KR, Lips KR (2014) Fungal infection intensity and zoospore output of Atelopus zeteki, a potential acute chytrid supershedder. PLOS ONE 9:e93356

Flores GE, Henley JB, Fierer N (2012) A direct PCR approach to accelerate analyses of human-associated microbial communities. PLOS ONE 7:e44563

* Garland S, Baker A, Phillott AD, Skerratt LF (2010) BSA reduces inhibition in a TaqMan ${ }^{\circledR}$ assay for the detection of Batrachochytrium dendrobatidis. Dis Aquat Org 92: 113-116

Gray MJ, Lewis JP, Nanjappa P, Klocke B and others (2015) Batrachochytrium salamandrivorans: the North American response and a call for action. PLOS Pathog 11: e1005251

* Hall EM, Brunner JL, Hutzenbiler B, Crespi EJ (2020) Salinity stress increases the severity of ranavirus epidemics in amphibian populations. Proc Biol Sci 287:20200062

*Hyatt AD, Boyle DG, Olsen V, Boyle DB and others (2007) Diagnostic assays and sampling protocols for the detection of Batrachochytrium dendrobatidis. Dis Aquat Org 73:175-192

Kriger KM, Hero JM, Ashton KJ (2006) Cost efficiency in the detection of chytridiomycosis using PCR assay. Dis Aquat Org 71:149-154

* Longo AV, Rodriguez D, da Silva Leite D, Toledo LF and others (2013) ITS1 copy number varies among Batrachochytrium dendrobatidis strains: implications for qPCR estimates of infection intensity from field-collected amphibian skin swabs. PLoS One 8:e59499

* McMahon T, Brannelly LA, Chatfield MWH, Johnson PTJ and others (2013) Chytrid fungus Batrachochytrium dendrobatidis has nonamphibian hosts and releases chemicals that cause pathology in the absence of infection. Proc Natl Acad Sci USA 110:210-215

R Core Team (2020) R: a language and environment for statistical computing. R Foundation of Statistical Computing, Vienna

* Rebollar EA, Woodhams DC, LaBumbard B, Kielgast J, Harris RN (2017) Prevalence and pathogen load estimates for the fungus Batrachochytrium dendrobatidis are impacted by ITS DNA copy number variation. Dis Aquat Org 123: 213-226

Reeder NMM, Pessier AP, Vredenburg VT (2012) A reservoir species for the emerging amphibian pathogen Batrachochytrium dendrobatidis thrives in a landscape decimated by disease. PLOS ONE 7:e33567

Robinson KA, Pereira KE, Bletz MC, Carter ED and others (2020) Isolation and maintenance of Batrachochytrium salamandrivorans cultures. Dis Aquat Org 140:1-11

Kockinger U, Funk M, Winter G (2021) Current approaches of 
preservation of cells during (freeze-) drying. J Pharm Sci 10:2873-2893

Sabino-Pinto J, Krause ET, Bletz MC, Martel A, Pasmans F, Steinfartz S, Vences M (2019a) Detectability vs. time and costs in pooled DNA extraction of cutaneous swabs: a study on the amphibian chytrid fungi. Amphib-Reptil 40:29-39

Sabino-Pinto J, Martel A, Pasmans F, Steinfartz S, Vences M (2019b) Pooling skin swabs does not inhibit qPCR detection of amphibian chytrid infection. PLOS ONE 14: e0214405

Schrader C, Schielke A, Ellerbroek L, Johne R (2012) PCR inhibitors-occurrence, properties and removal. J Appl Microbiol 113:1014-1026

Shin J, Bataille A, Kosch TA, Waldman B (2014) Swabbing often fails to detect amphibian chytridiomycosis under conditions of low infection load. PLOS ONE 9:e111091

Simpkins C, Van Sluys M, Hero JM (2014) Swabber effect: swabbing technique affects the detectability of Batrachochytrium dendrobatidis. Herpetol Rev 43:443-445

Smith HK, Pasmans F, Dhaenens M, Deforce D and others (2018) Skin mucosome activity as an indicator of Batrachochytrium salamandrivorans susceptibility in salamanders. PLOS ONE 13:e0199295

Standish I, Leis E, Schmitz N, Credico J and others (2018) Optimizing, validating, and field testing a multiplex qPCR for the detection of amphibian pathogens. Dis Aquat Org 129:1-13

Editorial responsibility: Catherine Collins,

Jouy-en-Josas, France

Reviewed by: L. Campbell and 2 anonymous referees
Stegen G, Pasmans F, Schmidt BR, Rouffaer LO and others (2017) Drivers of salamander extirpation mediated by Batrachochytrium salamandrivorans. Nature 544:353-356

* Videvall E, Strandh M, Engelbrecht A, Cloete S, Cornwallis CK (2017) Direct PCR offers a fast and reliable alternative to conventional DNA isolation methods for gut microbiomes. mSystems 2:00132-17

*Waddle JH, Grear DA, Mosher BA, Grant EHC and others (2020) Batrachochytrium salamandrivorans (Bsal) not detected in an intensive survey of wild North American amphibians. Sci Rep 10:13012

* Weldon C, Crottini A, Bollen A, Rabemananjara FCE, Copsey J, Garcia G, Andreone F (2013) Pre-emptive national monitoring plan for detecting the amphibian chytrid fungus in Madagascar. EcoHealth 10:234-240

* Wilber MQ, Knapp RA, Toothman M, Briggs CJ (2017) Resistance, tolerance and environmental transmission dynamics determine host extinction risk in a load-dependent amphibian disease. Ecol Lett 20:1169-1181

Woodhams DC, Brandt H, Baumgartner S, Kielgast J and others (2014) Interacting symbionts and immunity in the amphibian skin mucosome predict disease risk and probiotic effectiveness. PLOS ONE 9:e96375

Wyngaard GA, Chinnappa CC (1982) General biology and cytology of cyclopoids. In: Harrison FN, Cowden RR (eds) Developmental biology of freshwater invertebrates. Alan R. Liss, New York, NY, p 485-533

Submitted: March 19, 2021

Accepted: July 13, 2021

Proofs received from author(s): September 20, 2021 